\title{
Aspectos críticos da expansão das possibilidades de recursos tecnológicos na investigação criminal: a inteligência artificial no âmbito do sistema de controle e de punição
}

\begin{abstract}
Critical aspects of expansion of the possibilities of technological resources in criminal research: artificial intelligence within the control and punishment system
\end{abstract}

Francisco de Assis de França Júnior ${ }^{1}$

Universidade de Coimbra/Portugal fafjunior2016@gmail.com

http://lattes.cnpq.br/2739102277898461

(D) http://orcid.org/0000-0002-6958-920X

Bruno Cavalcante Leitão Santos ${ }^{2}$

Centro Universitário CESMAC e Faculdade de Ciências Jurídicas e Sociais de Maceió - Maceió/AL, Brasil brunoleitao.adv@hotmail.com http://lattes.cnpq.br/9699629460607799 https://orcid.org/0000-0001-7556-2348

\section{Felipe Costa Laurindo do Nascimento ${ }^{3}$}

Universidade Federal de Alagoas - Maceió/AL, Brasil felipe@felipelaurindo.com http://lattes.cnpq.br/4065784091972709

https://orcid.org/0000-0001-9524-4320

1 Doutorando e Mestre em direito pela Universidade de Coimbra (PT); Professor no Centro Universitário CESMAC (Maceió/AL); Advogado.

2 Doutor em Direito pela PUC-RS e Mestre em Direito Público pela UFAL, professor de Direito Penal no Centro Universitário CESMAC (Maceió/AL) e na Faculdade de Ciências Jurídicas e Sociais de Maceió - FAMA.

3 Mestre pela Universidade Federal de Alagoas - UFAL. 
RESUMo: O presente artigo tem como objetivo principal analisar criticamente as potenciais influências negativas da utilização de novas tecnologias no sistema de controle e de punição. Dada a quantidade de ferramentas atualmente gestadas, tanto pelos governos quanto pela iniciativa privada, optamos por uma análise do tipo panorâmica, propondo inicialmente uma espécie de cenário possível da dinâmica do processo de investigação. O problema central com o qual nos preocupamos é a expansão da intervenção estatal e privada nas liberdades individuais, o que se reflete na restrição de garantias processuais, atingindo diretamente a dignidade da pessoa humana, mesmo que se argumente a necessidade de uma paridade entre acusação e defesa. Partindo-se de uma pontual revisão bibliográfica sobre a utilização de máquinas com inteligência artificial na investigação, articulando literatura situada entre a tecnologia e o direito, com base principal no método hipotético dedutivo, concluímos não pela necessidade de expandir, mas de limitar, em praticamente todos os aspectos, a utilização de máquinas com inteligência artificial e a disseminação de potenciais investigadores criminais.

Palavras-chave: Inteligência artificial; Sistema de controle e de punição; Dignidade humana.

ABSTRACT: This article aims to critically analyze the potential negative influences of the use of new technologies in the control and punishment system. Given the amount of tools currently managed, both by governments and the private sector, we opted for a panoramic analysis, initially proposing a kind of possible scenario for the dynamics of the investigation process. The central problem with which we are concerned is the expansion of state and private intervention in individual freedoms, which is reflected in the restriction of procedural guarantees, directly affecting the dignity of the human person, even if it argues the need for a parity between the accusation and defense. Starting from a punctual bibliographic review on the use of machines with artificial intelligence in research, articulating literature located between technology and law, based mainly on the hypothetical deductive method, we conclude not by the need to expand, but to limit, in practically all aspects, the use of artificial intelligence machines and the dissemination of potential criminal investigators.

KeYwords: Artificial intelligence; Control and punishment system; Human dignity. 


\section{INTRODUÇÃO}

Coração acelerado, estômago contraído, respiração alterada, transpiração intensa, desequilíbrio hormonal, entre outras alterações características da ansiedade, do nervosismo e da irritação são detectadas por um micro aparelho implantado cirurgicamente no corpo humano. Dotado de um avançado programa informático, o aparelho capta também os impulsos elétricos do cérebro de seu hospedeiro, aprendendo, em um pequeno lapso de tempo, o padrão de seu funcionamento. Obtém-se uma espécie de impressão mental da pessoa, uma cópia virtualizada, um "espelho", de sua forma de pensar. Por essa lógica investigativa, daria, portanto, para sabermos o que a pessoa faria numa determinada situação. O processamento de todas essas informações, obtidas através dos referidos estímulos bio-químico-elétricos, serviria para desvendar crimes e para alertar as autoridades sobre providências recomendáveis (ou talvez até impostas) para os evitar (ou tentar resolvê-los).

Imagine-se que a propositura de tal aparelho como mecanismo de alegada prevenção no âmbito de um projeto de lei nacional, evidentemente, provocaria intensas discussões. Pressuponha-se que a ideia fosse de que a implantação se desse apenas nos corpos dos já condenados por crimes hediondos. Com o tempo, logo se levantariam vozes no sentido de que seria preciso ampliar o público alvo. A bancada de parlamentares que se denomina especialista em segurança pública - seduzida pelos interesses econômicos da indústria informática, que já lhes teria apresentado as inovadoras lentes de contato com microcâmera -, a mesma que logo se veria apoiada pelos autointitulados defensores da família, haveria de concluir que, afinal, o aparelhinho não deveria ser temido pelos cidadãos de bem. Em resumo, entre os entusiasmados pela ideia de prevenção e os que ponderariam a indevida invasão à privacidade (física e mental) e à dignidade humanas, certamente prevaleceriam aqueles.

Não tardaria e todas as pessoas teriam de se submeter a um (ainda mais) apertado controle social no curso de suas vidas. Com a utilização desses novos mecanismos de observação/vigilância/controle, que aparentemente intencionam evitar/solucionar conflitos, as pessoas são impelidas a seguir um agonizante padrão comportamental. O que importa não é propriamente o que eu faço, mas como o que eu faço 
será interpretado por quem me observa/assiste/vigia/controla. Será preciso evitar as tais atitudes suspeitas para não ser incomodado pela atuação não muito sutil dos agentes desse poderoso sistema de controle e de punição estatal. Um reduzido grupo de pessoas, responsável pela programação desses aparelhos, possuem o poder de gerir diretamente a própria dinâmica social.

Não será preciso muito esforço para percebermos que a ideia de que o interesse público haverá de prevalecer sobre os obstáculos representados por direitos e garantias individuais é disseminada de maneira triunfante pelo mundo, sobretudo em países que se anunciam como democráticos. A conhecida máxima de quem não deve não teme tem sido levada até às últimas consequências pelas autoridades constituídas, utilizando-se as informações obtidas, mais do que para a solução de conflitos, mas sobretudo para a perpetuação do status de gestor da moral de parte importante da dinâmica social. Integrantes do Judiciário, do Ministério Público e das polícias, com raríssimas exceções, disputam cada vez mais espaços nesse exercício do poder investigativo/punitivo. Sem mencionarmos, ao menos por agora, os espaços concedidos tanto a detetives particulares (Lei n. 13.432/2017) quanto à advocacia (Provimento n. 188/2018), em que, embora se intencione, no fundo, uma necessária "paridade de armas" na relação entre o Estado e o indivíduo investigado, a inciativa tendencione diminuir os espaços para o desenvolvimento da individualidade e, por consequência, da própria dignidade humana.

É inegável que ideias que nos pareciam exequíveis apenas nos filmes de ficção hollywoodianos estão cada vez mais palpáveis. Para que se tenha uma ligeira noção do atual estado da arte, nos Estados Unidos, o laboratório de inteligência artificial do Instituto de Tecnologia de Massachusetts tem desenvolvido um dispositivo capaz de identificar, através de sinais sem fio, emoções humanas. ${ }^{4}$ Já em Nova Iorque, pesquisadores da Universidade de Stony Brook anunciaram que têm manipulado a memória

4 Perceba-se que a ideia inovadora de implantação cirúrgica de um aparelho, anteriormente mencionada, já se insinua como obsoleta, pois, com o avanço tecnológico, o que se percebe é que sequer será preciso algum contato físico com quem se quer investigar/punir. CONNER-SIMONS, Adam; GORDON, Rachel. Detecting emotions with wireless signals. Disponível em: https://www.csail.mit. edu/detecting_emotions_with_wireless_signals. Acesso em: 16 fev. 2020. 
de ratos. ${ }^{5}$ Em Pittsburgh, na Universidade Carnegie Mellon, já se tem trabalhado em projeto de impressão cerebral. ${ }^{6}$ Entretanto, se prosseguíssemos, veríamos rapidamente que não apenas as mais destacadas instituições de ensino dos Estados Unidos estão envolvidas com esse tipo de pesquisa.

Perceba-se ainda que a Tesla, uma destacada empresa do ramo automotivo - a mesma que promete inserir no mercado carros autônomos que permitirão que os motoristas literalmente durmam sem se preocuparem com o trânsito ${ }^{7}$-, apresentou em 2017 um caminhão elétrico equipado com um avançado sistema de pilotagem automática. Além de freios inteligentes, o veículo conta ainda com estabilizadores para manter o automóvel sempre na pista correta. ${ }^{8}$ Nesse mesmo contexto de acelerada inovação tecnológica, a Samsung, uma empresa que atua nos diversos ramos da tecnologia da informação, anunciou em 2016 investimentos em projeto para a produção de lentes de contato dotadas de microcâmera e acesso à internet, capazes de fotografar, filmar e reproduzir imagens do cotidiano. ${ }^{9}$

Para que não se imagine que o Brasil esteja à margem desse processo, além de valer-se de um sistema eleitoral, desde 2000, dependente

5 LEONARDI, Ana Carolina. Cientistas conseguem apagar memórias ruins em ratos - Eles descobriram que, manipulando um neurotransmissor, conseguem deletar traumas e até reforçar memórias boas. Disponível em: https://super. abril.com.br/ciencia/cientistas-conseguem-apagar-memorias-ruins-em-ratos/. Acesso em 16 fev. 2020.

6 GREGOIRE, Carolyn. Scientists Have Figured Out How To 'Fingerprint' Your Brain - The technology could be used to predict mental or neurological illness. Disponível em: https://www.huffingtonpost.com/entry/brain-connections-map_us_582b628be4b01d8a014adc56. Acesso em: 16 fev. 2020.

7 NOVET, Jordan. Tesla is working with AMD to develop its own A.I. chip for self-driving cars, says source. Disponível em: https://www.cnbc. com/2017/09/20/tesla-building-an-ai-chip-for-its-cars-with-amd.html. Acesso em 16 fev. 2020.

8 MARSHALL, Aarian. What does tesla's automated truck mean for truckers? Disponível em: https://www.wired.com/story/what-does-teslas-truckmean-for-truckers/. Acesso em 16 fev. 2020.

9 D’ANGELO, Helô. Vem aí: lentes de contato de realidade virtual - A Samsung acaba de registrar uma patente para a produção de lentes com microcâmeras integradas e conexão wi-fi. Disponível em: https://super.abril.com.br/ tecnologia/vem-ai-lentes-de-contato-de-realidade-virtual/. Acesso em 16 fev. 2020. 
da informatização, ${ }^{10}$ as autoridades do país se utilizam, com cada vez mais frequência, das inúmeras ferramentas oferecidas pela tecnologia para gerir os milhões de processos que tem tramitado em seus órgãos jurisdicionais. ${ }^{11} \mathrm{~A}$ propósito, a prática de atos processuais por meio eletrônico tem sido objeto de interesse do legislativo brasileiro desde o início da década 1990, quando se aprovou a Lei do Inquilinato (Lei 8.245/91). ${ }^{12}$ Após uma série de outras iniciativas, tem-se ainda o advento da Lei 11.419/06, que dispõe sobre a informatização do processo judicial no Brasil. Em seguida, com o intuito de uniformizar a tramitação processual eletrônica no país, ${ }^{13}$ o Conselho Nacional de Justiça emitiu a Resolução 16, de 25 de abril de 2012, adotando, de forma exclusiva, o sistema do Processo Judicial Eletrônico. ${ }^{14}$ Os exemplos, portanto, abundam.

10 BRASIL. Tribunal Superior Eleitoral. Eleições Seguras: saiba como surgiu a urna eletrônica e por que ela está em constante processo de evolução. Disponível em: http://www.tse.jus.br/imprensa/noticias-tse/2016/Agosto/eleicoesseguras-saiba-como-surgiu-a-urna-eletronica-e-por-que-ela-esta-em-constante-processo-de-evolucao. Acesso em 16 fev. 2020.

11 BRASIL. Conselho Nacional de Justiça. Justiça em Números 2019: ano-base 2018. Disponível em: https://www.cnj.jus.br/wp-content/uploads/2019/08/ b60a659e5d5cb79337945c1dd137496c.pdf. Acesso em 16 fev. 2020; CANÁRIO, Pedro. Judiciário brasileiro tem 80,1 milhões de processos em tramitação. Disponível em: https://www.conjur.com.br/2018-ago-27/judiciario-brasileiro-801-milhoes-processos-tramitacao. Acesso em 16 fev. 2020.

12 O referido diploma legal determinou que, havendo autorização no contrato, a citação, intimação ou notificação, nas ações de despejo, consignação em pagamento de aluguel e acessório da locação, revisionais de aluguel e renovatórias de locação, desde que endereçadas a pessoa jurídica ou firma individual, poderiam ser realizadas por meio de telex ou fax, abrindo caminho, inclusive, para a utilização de outros meios eletrônicos de comunicação dos atos do processo. Veja-se: VENOSA, Sílvio de Salvo. Lei do inquilinato comentada: doutrina e prática. São Paulo: Atlas, 2013. p. 280.

13 Mesmo com o esforço do Conselho Nacional de Justiça ainda não há uma uniformização, tendo em vista que os tribunais brasileiros ainda utilizam os mais diversos sistemas. Esses tribunais vêm conseguindo, através de decisões do próprio Conselho Nacional de Justiça, adiar a implantação do Processo Judicial Eletrônico em suas unidades, dilatando os prazos estipulados no artigo 34 , § $3^{\circ}$ da Resolução do CNJ n ${ }^{\circ} 185 / 2013$.

14 BRASIL. Tribunal Regional Federal da $5^{\circ}$ Região. Resolução no 16, de 25 de abril de 2012. Disponível em: http://www.trf5.jus.br/downloads/RESOLUCAO\%20No\%2016\%20DE\%2025\%20DE\%20ABRIL\%20DE\%202012.pdf. Acesso em 16 fev. 2020. 
Eis uma estrutura, com recurso à inteligência artificial, que contemporaneamente tem se desenvolvido e que é plenamente capaz de nos levar, em curto espaço de tempo, a um cenário muito parecido com algum dos mais elaborados filmes de ficção científica hollywoodianos. Em razão disso, as questões que nos preocupam, e, portanto, as problematizações propostas para o presente artigo, são: como compatibilizar esses avanços tecnológicos com os direitos e garantias individuais? Ampliar o poder investigatório à advocacia, por exemplo, poderia ajudar? Qual a melhor maneira, da perspectiva jurídica, de lidarmos, por exemplo, com robots, drones e até avatares? Como nos relacionar com esses mecanismos oferecidos pela (pós)modernidade e que são capazes de abrigar uma inteligência do tipo artificial? Assim, nosso objetivo principal é avaliar criticamente, ainda que de maneira sucinta, o potencial impacto negativo que essas ferramentas possuem no funcionamento dos sistemas de controle e de punição e na fruição das liberdades individuais.

A partir de uma pontual revisão bibliográfica, pretendemos demonstrar que, embora estejamos num caminho sem volta relativamente ao uso dessas tecnologias, será preciso todo o cuidado para que pessoas (ou grupos) com discursos totalitários não se apropriem de tais recursos para a manutenção e a desembaraçada ampliação do exercício do poder punitivo. Por mais engenhosas que sejam essas invenções, será preciso reconhecer limites em suas utilizações, sobretudo quando estivermos diante de interferências junto à dignidade humana. Desse modo, sem qualquer pretensão de esgotarmos o assunto, nossa contribuição vai no sentido de chamar a atenção da comunidade jurídico-acadêmica - infelizmente ainda pouco produtiva nessa temática -, para que volte seus esforços para discutir um cenário que, mais cedo ou mais tarde, há de se fazer agudamente presente, modificando muitas das concepções atualmente encaradas como sólidas em ambiente que se pretende democrático.

\section{INTELIGÊNCIA ARTIFICIAL: PODE UMA MÁQUINA PENSAR?}

Saber exatamente como funciona o cérebro humano ainda é um incômodo mistério, mesmo para os pesquisadores mais experientes. ${ }^{15} \mathrm{~A}$

15 SEARLE, John. Mente, cérebro e ciência. Trad. Artur Morão. Lisboa: Edições 70, 2015. p. 11 ss. 
constatação inquieta justamente porque se trata de um órgão que ocupa uma função central no funcionamento do corpo humano. Trata-se, basicamente, de nosso centro de gerenciamento. Aliás, grosso modo, é o que nos permite ter consciência, pensar, refletir, desejar, articular as ideias, tomar decisões importantes, entre outras coisas. Nessa área extremamente complexa da pesquisa científica, o certo é que nós ainda não sabemos exatamente todas as nuances das relações estabelecidas entre o cérebro e o resto do corpo. Há tempos que neurocientistas, psicólogos, filósofos e até mesmo juristas têm interagido na esperança de oferecer respostas às muitas perguntas ainda em aberto. São, portanto, muitos os caminhos possíveis para o desenvolvimento da presente questão.

Percebe-se rapidamente que o cérebro oferece um manancial riquíssimo aos pesquisadores dos diversos ramos do conhecimento. Ocorre que, o resultado de uma pesquisa (que se pretende) científica, como sabemos, é fruto de uma série de fatores, dentre os quais - certamente um dos mais importantes -, a metodologia escolhida para lidar com o objeto de interesse. ${ }^{16}$ Nesse sentido, importa-nos alertar: aqui, vamos tentar, tanto quanto possível, passar ao largo das controvérsias mais destacadas sobre o assunto, tendo em vista que, pelo viés mais conciso da abordagem que escolhemos realizar, o objetivo é o de tão somente oferecer uma visão panorâmica da problemática proposta, de estimular o debate, deixando à mostra, além das fontes que reputamos como imprescindíveis para o aprofundamento, um espaço para que o leitor ou leitora, se quiser, possa realizar suas necessárias reflexões críticas.

Conquanto, é evidente, será preciso assumirmos posições. É, aliás, o comportamento que se deve esperar num texto que se pretende, antes de qualquer outra coisa, crítico, como é nossa proposta. No entanto, essas posições não devem seguir um critério do tipo casuístico. Muito pelo contrário. Elas precisam servir para construir uma linha de raciocínio que guarde alguma coerência, ou seja, devem gravitar em torno de uma ideia fundante que lhes mantenham sempre conectadas umas às outras. Ao estilo kantiano. No caso presente, esse núcleo essencial será constituído pela necessidade de respeito à dignidade humana. Nenhuma inovação

16 CROSSEN, Cynthia. O fundo falso das pesquisas - a ciência das verdades torcidas. Trad. Roberto Teixeira. Rio de Janeiro: Revan, 1996. 
tecnológica, por qualquer que seja o argumento, ou por qualquer que seja a pessoa, há de se sustentar legitimamente num ambiente que se pretende democrático se puser em causa a dignidade humana. Eis as bases sobre as quais refletiremos criticamente adiante.

Dito isso, como já se anunciou, convém começarmos por perguntar o que, nesse início de debate, parece-nos fundamental: pode uma máquina pensar? É muito comum, diz-nos John Searle ${ }^{17}$, nos depararmos com analogias entre o funcionamento do cérebro humano e computadores digitais, sendo, aliás, o cérebro encarado como um hardware e a mente como um software. Não é raro, portanto, nos depararmos com quem pretenda atribuir essa capacidade, outrora perspectivada como exclusiva dos seres humanos, aos computadores. ${ }^{18}$ Desse modo de ver as coisas, a resposta ao questionamento feito seria positiva. Ocorre que, esse tipo de afirmação, de modo geral, baseia-se numa premissa que não se sustenta. Parte da ideia de que o cérebro, tal como os computadores, estaria lastreado em termos puramente formais, alcançados pelos seus programadores, o que não é verdade. A mente humana, que é o que de fato nos permite pensar, é fruto do comportamento dos elementos constitutivos do cérebro, logo, fazem parte de um complexo fenômeno químico e biológico.

Embora tenhamos driblado outro questionamento tão importante quanto o que acabamos de fazer, nossa conclusão não há de ruir por qualquer abalo provocado pela crítica, mesmo porque também esse conceito é permeado de controvérsias, ${ }^{19}$ o que demanda, em tais casos, uma tomada de posição. Refere-se aqui à definição do ato de pensar. Logo, é de se perceber que, se é da mente que vem o pensamento, não a possuindo uma máquina, não há com concebê-la como um ser pensante. Desse modo, o que se deve atribuir a uma máquina é a capacidade, que pode vir a ser mais ou menos forte, de dar respostas com base na articulação mecânica de determinadas informações. Embora não seja nossa

17 O questionamento feito, bem como o desenvolvimento deste parágrafo, é baseado na obra do autor: SEARLE, John. Mente, cérebro e ciência. Trad. Artur Morão. Lisboa: Edições 70, 2015. p. 37.

18 Ver: HELM, Gerhard. Computer können denken! Der Mensch in der Perspektive der Kognitionswissenschaft. Frankfurt am Main: Suhrkamp, 1998.

19 PEREIRA, Luís Moniz. A máquina iluminada - cognição e computação. Porto: Fronteira do Caos, 2016. p. 27 ss. 
intenção uma conceituação acabada - se é que isso seja possível -, é esse o tipo de dinâmica que, grosso modo, constitui o que chamamos de inteligência artificial. ${ }^{20}$ Nela, não haverá criação genuína, mas uma imitação, espartilhada por sua programação, com velocidade e fiabilidade - aí sim! - quase sempre superiores às capacidades humanas. ${ }^{21}$

Registre-se, para que não percamos os créditos pelo pioneirismo, em ligeira contextualização histórica, que foi em meados dos anos de 1950, nos Estados Unidos, que essa ferramenta começa a ser desenvolvida com dedicado interesse. John MacCarthy, apontado como o criador do termo inteligencia artificial, Marvin Minsky, Herbert Simon e Allen Newell, no verão de 1956, em New Hampshire, reuniram-se com uma série de outros pesquisadores para exploração das ideias inovadoras que não paravam de surgir sobre a temática. Na perspectiva de Howard Gardner ${ }^{22}$, a década anterior já havia assistido "às ideias brilhantes de uma geração mais velha" - formada basicamente pelas contribuições de Norbert Wiener,

20 "Acreditamos, pois, que a inteligência não depende de um determinado substrato físico. Ou seja, a inteligência não está só no ser humano, mas existe também no animal e no extraterrestre, como se supõe. O mesmo acontece com os computadores, onde a inteligência também pode existir”. PEREIRA, Luís Moniz. A máquina iluminada - cognição e computação. Porto: Fronteira do Caos, 2016. p. 51. Sobre seu conceito, história, desenvolvimento e atual estado da arte, recomenda-se, por todos: RUSSELL, Stuart J.; NORVIG, Peter. Artificial Intelligence - a modern approach. 3. ed. New Jersey: Pearson, 2010. Para Stephen Hawking, não há "qualquer razão que explique por que não pode a inteligência ser simulada num computador”. PENROSE, Roger. O grande, o pequeno e a mente humana - com Abner Shimony, Nancy Cartwright e Stephen Hawking. Trad. David Resendes. Lisboa: Gradiva, 2003. p. 173. Roger Penrose tem uma visão crítica a esse respeito, atribuindo uma "verdadeira inteligência" à consciência (capacidade de formação de juízos), o que faltaria às máquinas: PENROSE, Roger. A mente virtual (the emperor's new mind) - sobre computadores, mentes e as leis da física. Trad. Augusto José Franco de Oliveira, Carlos Lourenço e Luís Teixeira da Costa. Lisboa: Gradiva, 1997. p. 531 ss. PENROSE, Roger. A mente virtual (the emperor's new mind) - sobre computadores, mentes e as leis da física. Trad. Augusto José Franco de Oliveira, Carlos Lourenço e Luís Teixeira da Costa. Lisboa: Gradiva, 1997. p. 27-28.

22 A construção de todo esse parágrafo de contextualização histórica deve-se às informações encontradas em: GARDNER, Howard. A nova ciência da mente - uma história da Revolução Cognitiva. Trad. Inês Ricardo, Lisboa: Relógio D’Água, 2002. p. 194-196. E mais: McCORDUCK, Pamela. Machines Who Think. São Francisco: W.H. Freeman, 1979. 
John von Neumenn, Warren McCulloch e Alan Turing -, "todas elas no sentido de concepção de computadores electrónicos, capazes de realizar funções normalmente associadas ao cérebro humano".

O fato é que essas máquinas já estão presentes na vida de praticamente todas as pessoas. E é justamente por isso que, por vezes, as tecnologias que abrigam têm nos apresentado uma série crescente de preocupações. Em um dos eventos mais emblemáticos nessa área, intitulado Web Summit - que tem se dedicado ao debate sobre tecnologia e inovação -, realizado no início de novembro de 2017, em Lisboa, Portugal, Stephen Hawking ${ }^{23}$ demonstrou sua preocupação com o uso da inteligência artificial. O físico britânico, mesmo dizendo-se um otimista, reconheceu que a "inteligência artificial pode ser a melhor ou a pior coisa para a humanidade", que essa é uma ferramenta que deve ser utilizada "para o bem do mundo", embora fosse preciso termos ciência "dos perigos, identificá-los e empregar a melhor prática e gestão e preparar as consequências do seu avanço com bastante antecedência”.

Ainda no evento, com a participação de cerca de 60 mil pessoas de 170 países diferentes, apresentou-se entusiasticamente uma personagem saudita incomum: Sophia, era o primeiro robot dotado de cidadania. Não bastasse o fato de ser a primeira máquina a ganhar cidadania, sua apresentação acabou objeto de intensas discussões entre os grupos de defesa dos direitos humanos, vez que, Sophia, que se apresentava como a representação de uma mulher, não portava as vestes tradicionais das mulheres sauditas. Como se sabe, na Arábia Saudita, regida pela lei islâmica, a condição sociocultural que se impõe às mulheres é ainda muito inferior àquela historicamente atribuída aos homens. Em público, precisam, por exemplo, cobrir com um lenço parte da cabeça. Assim, Sophia já teria nascido com mais direitos e garantias do que as mulheres sauditas de carne e osso. ${ }^{24}$

${ }^{23}$ HAWKING, Stephen. Conferência de abertura da Web Summit em Lisboa, Portugal. Disponível em: https://www.youtube.com/watch?time_continue $=13 \& v=U-h c S L y a 0 \_w$. Acesso em 16 fev. 2020.

24 PINTO, Rita. Sophia, a robot que já tem mais direitos que as mulheres na Arábia Saudita. Disponível em: https://shifter.pt/2017/10/sophia-robot-arabia-saudita/. Acesso em 16 nov. 2017. 
Em 16 de novembro de 2017, no auditório da Faculdade de Direito da Universidade de Coimbra, em Portugal, profissionais de diversas áreas, vinculados especialmente às questões jurídicas, dedicaram-se a discutir, no âmbito do Congresso Direito e Robótica, alguns dos problemas provenientes da utilização dessas novas tecnologias na dinâmica social. ${ }^{25}$ Desde questões relacionadas ao mercado de trabalho, com a preocupação de que robots acabem por substituir seres humanos nas linhas de produção das grandes empresas - máquinas que, segundo João Leal $\mathrm{Amado}^{26}$, não descansam, não adoecem, não têm filhos, não fazem greves, mas que também não consomem -, passando pela possibilidade de negociação diretamente realizada entre as máquinas, até questões sobre a responsabilidade civil, estiveram em debate.

Conforme destacado por António Pinto Monteiro ${ }^{27}$, o Parlamento Europeu emitiu uma Resolução, de 16 de fevereiro de 2017, com recomendações a respeito da interação entre o Direito Civil e a Robótica, inclusive com o reconhecimento de uma espécie de personalidade eletrônica. Em uma das inúmeras disposições, objeto de discussão desencadeada por Nathalie Nevejans ${ }^{28}$, observa-se que na alínea $f$ ) do artigo 59 prevê-se estabelecer "um estatuto jurídico específico para os robôs a longo prazo, de modo a que, pelo menos os robôs autónomos mais sofisticados possam ser determinados como detentores do estatuto de pessoas eletrônicas responsáveis por sanar quaisquer danos que possam causar e, eventualmente, aplicar a personalidade eletrônica a casos em que os robôs tomam

25 Um debate semelhante também pode ser encontrado, numa edição especial, em: MARTINHO, Rui Leão (dir.). Cadernos de economia, Lisboa, ano XXX, n. 119, abr/jun, 2017.

26 LEAL AMADO, João. Os robots e o direito do trabalho: o desafio final? In: Congresso Direito e Robótica. Auditório da Faculdade de Direito da Universidade de Coimbra. 16 de nov. 2017.

27 PINTO MONTEIRO, António. Intervenção de abertura. Congresso Direito e Robótica. Auditório da Faculdade de Direito da Universidade de Coimbra. 16 de nov. 2017.

NEVEJANS, Nathalie. Quel statu juridique pour les robots autonomes? A propos de l'article 59, f), de la Résolution du Parlament européen du 16 février 2017 sur les règles de droit civil sur la robotique. In: Congresso Direito e Robótica. Auditório da Faculdade de Direito da Universidade de Coimbra. 16 de nov. 2017. 
decisões autónomas ou em que interagem por qualquer outro modo com terceiros de forma independente".

De qualquer modo, não nos seria possível prescrever com exatidão o que nos reserva o futuro relativamente às tecnologias. Entretanto, uma coisa garantidamente nos é permitido afirmar: quanto maior for a quantidade de pessoas a utilizá-la em uma investigação criminal, maiores devem ser as preocupações quanto à possibilidade de erosão dos valores que tradicionalmente sustentam uma democracia. Apesar de nossa clara tomada de posição, importa frisar que convém deixarmos a porta entreaberta para que possamos continuar a discutir todas essas questões no futuro. Mesmo porque, na esteira do que nos diz John Searle ${ }^{29}$, o vocabulário conhecido hoje talvez não seja completamente capaz de nos levar a compreender como será a dinâmica social no futuro. Certamente teremos categorias conceituais, e até elementos, que hoje não conhecemos e que, portanto, o vocabulário do século XXI pode não nos ser útil para as coisas do século XXII, XXIII e assim por diante. Com o aparecimento do disquete, no início dos anos de 1970, não falávamos, por exemplo, no Compact Disc, que surgiu apenas no final da década de 1980. Com o aparecimento desse, também não falávamos no pen drive. E atualmente o armazenamento de dados já é feito em nuvens ou coisas do gênero.

Não nos custa ainda lembrar que robots que "pensam" e que são movidos até por estados emocionais tem sido a matéria prima de diversos tipos de arte. Vale destacar que no cinema e na literatura elas tem abundado. A obra de um dos mais destacados autores nessa área tem servido para alimentar (ainda mais) as especulações a respeito do tema aqui enfrentado. O escritor russo Isaac Asimov ${ }^{30}$, por exemplo, acabou por imortalizar as três mais popularizadas e citadas leis da robótica, quais sejam: 1) um robot não pode causar dano a um ser humano nem,

29 SEARLE, John. Mente, cérebro e ciência. Trad. Artur Morão. Lisboa: Edições 70, 2015. p. 19.

30 Recomendam-se, em especial: ASIMOV, Isaac. Eu, Robot. Trad. Eduardo Saló, José Teixeira de Aguilar e Mário Redondo. Mem Martins: Europa-América, 2004; ASIMOV, Isaac. O homem bicentenário e outras histórias. Trad. Milton Persson. Porto Alegre: L\&PM, 1997; ASIMOV, Isaac. Visões de um robot. Trad. Eduardo Saló. Mem Martins: Europa-América, 1992. 
por inação, permitir que qualquer humano sofra danos; 2) um robot deve cumprir as ordens que lhe forem dadas por seres humanos, exceto nos casos em que essas ordens colidam com a primeira lei; e 3) um robot deve proteger a própria existência, desde que essa proteção não colida com a primeira ou com a segunda lei.

Ray Kurzweil ${ }^{31}$, por sua vez, sustenta que ainda no século XXI os seres humanos não serão a espécie mais inteligente e capaz do planeta. O futurista explica que os computadores dobravam a sua velocidade a cada três anos no início do século XX, baixando para dois anos na década de 50 do século passado, e atualmente dobram a velocidade e capacidade de processamento em um espaço de aproximadamente oito meses. O autor afirma que essa marcha vai continuar até que por volta de 2020, e que os computadores conseguiriam a capacidade de memória e processamento igual a de um cérebro humano (até aqui não se tem notícia de tal feito), o que não quer dizer que irão ter a mesma flexibilidade da inteligência humana. Descrevendo a evolução como uma tecnologia que possibilitou a raça humana a criar a inteligência artificial disponível em nossos tempos, argumenta como natural a possibilidade de que a própria tecnologia crie a próxima tecnologia mais inteligente, e assim por diante. Prevê que a tendência no final do século XXI será a de uma fusão entre a inteligência humana e a artificial, não havendo mais uma distinção clara entre humanos e computadores.

Dessa perspectiva, a inteligência artificial reivindicaria a qualidade de "ser humano", e as pessoas que não utilizassem dispositivos ubíquos não teriam mais a capacidade de participar de simples diálogos, que com a quantidade de informações que poderiam conter, estariam fora do alcance de uma mente apenas humana. O fato é que ritmo da mudança da tecnologia se acelera, e sua força se expande de forma exponencial. Isso leva o autor acima mencionado a afirmar que, no futuro, a informação baseada na tecnologia irá englobar todo o conhecimento e capacidade humanas, incluindo as habilidades emocionais, a moralidade, e até mesmo o próprio

31 KURZWEIL, Ray. The age of spiritual machines: when computer exceed human intelligence. New York: Penguin Books, 1999. 
cérebro como um todo. ${ }^{32}$ Em obra mais recente ${ }^{33}$, exalta a forma como o nosso sistema biológico codificou as informações que foram necessárias para a longevidade da raça humana e o seu desenvolvimento. Exalta ainda a importância do estudo do cérebro humano, problematizando acerca de uma teoria que visa descrever o algoritmo básico no neocórtex (região do cérebro responsável pela percepção, memória e pensamento crítico), tendo em vista que a existência de um padrão utilizado conscientemente por essa região que já seria, em parte, reproduzido por dispositivos como o Watson (inteligência artificial desenvolvida pela IBM que é capaz de processar milhares de páginas em linguagem natural e responder as mais variadas perguntas, tendo, inclusive, vencido uma competição de perguntas e respostas onde concorreu com humanos) ${ }^{34}$, e o Siri (assistente pessoal presente em computadores e dispositivos móveis da Apple).

Porém, seja como for, da nossa perspectiva, não é de se admitir que um computador, por mais avançado que seja, possa vir a efetivamente pensar. Com Terry Winograd, lembrado oportunamente por Guitta Pessis-Pasternak ${ }^{35}$, podemos afirmar que "o computador nunca será capaz de enfrentar todas as situações previstas, porque não possui a aptidão espontânea do cérebro". As máquinas reagem às informações que lhes são repassadas conforme o previsto nas fórmulas matematicamente moldadas (ou no algorítimo) para o âmbito de sua programação. Erros acontecem, evidentemente. Assim, embora não pensem, evidentemente isso não significa dizer que não tenhamos que nos preocupar com as consequências da utilização dessas máquinas. Para dizê-lo mais diretamente: o receio que se deve ter das máquinas, que proliferam, quer gostemos ou não, está relacionado não com sua quantidade ou variedade, mas com seu uso (por vezes indevido) pelos seres pensantes, logo, aqueles encarados como humanos.

32 KURZWEIL, Ray. The singularity ir near: when humans transcend biology. London: Duckworth Overllok, 2008.

33 KURZWEIL, Ray. How to Create a Mind: The Secret of Human Thought Revealed. London: Duckworth Overllok, 2013.

34 GABBATT, Adam. IBM computer Watson wins Jeopardy clash. Disponível em: https://www.theguardian.com/technology/2011/feb/17/ibm-computerwatson-wins-jeopardy. Acesso em 16 fev. 2020.

35 PESSIS-PASTERNAK, Guitta. Será preciso queimar Descartes? Do caos à inteligência artificial: quando os cientistas se interrogam. Lisboa: Relógio D’Água, 1993. p.189. 


\section{O IMPACto da tecnologia No ÂMBITO do SISTEMA DE CONTROLE E DE PUNIÇÃO: PERSPECTIVAS NEGATIVAS DE UM FUTURO NÃO MUITO DISTANTE}

Uma dinâmica social dirigida por máquinas, que nos observam constantemente, já não é mais só produto de uma mente que fertilmente perspectivava o futuro da humanidade. Nesse sentido, através da linguagem da ficção científica, como já dissemos, as produções hollywoodianas sempre foram fartas. A lógica do Grande Irmão, que nos havia sido apresentada por George Orwell ${ }^{36}$ no final da década de 1940, ainda sob o rescaldo da Segunda Grande Guerra, deixou de ser uma mera aposta e tem passado a interagir conosco de maneira cada vez mais intensa no cotidiano. Além das penitenciárias, também hospitais, escolas, bancos, repartições públicas de um modo geral e até ruas, praças, avenidas e residências particulares, em praticamente todos os locais em que as pessoas têm alguma condição financeira, as ferramentas de vigilância e de controle estão presentes. Câmeras, por exemplo, que permitem ao adquirente acompanhar, de onde estiver, o que se passa no local de seu interesse, espalham-se por ambientes públicos e particulares, além de drones que já auxiliam na retomada do mercado imobiliário americano ${ }^{37}$, servindo de instrumento para o incremento dos negócios.

Desde 2001, com a derrubada das torres gêmeas em Nova Iorque, no coração dos Estados Unidos, incursões terroristas em diversos outros países, sobretudo naqueles encarados como desenvolvidos, acabaram por facilitar o desencadeamento de um processo de alargamento da presença de determinados agentes públicos na vida particular das pessoas. Num dos inúmeros estudos já disponibilizados sobre os impactos desse fenômeno na dinâmica social, apontando para o valor dos caracteres estéticos como critério para utilização da tecnologia do videomonitoramento, chegou-se à conclusão de que "duas categorias sociais eram também visadas com base na sua aparência: os jovens, em especial os que tinham um aspecto

36 ORWELL, George. 1984. Trad. Heloisa Jahn. São Paulo: Companhia das Letras, 2009.

37 GLINK, Llyce. 9 ways drones are changing real estate. Disponível em: https:// www.cbsnews.com/media/9-ways-drones-are-changing-real-estate/. Acesso em 16 fev. 2020. 
descuidado, e as mulheres bem-parecidas". No caso das mulheres, os corpos "viam-se mais expostos ao olhar electrónico" sob uma perspectiva voyeurista. ${ }^{38}$ Ironicamente, agora dizemos nós, boa parte dos gestores dessa estrutura alega estar à serviço da moral e dos bons costumes.

O objetivo desse sistema é, primariamente, a prevenção. Os discursos de justificação são sempre nesse sentido. Parte-se do pressuposto de que quanto mais vigiado o sujeito estiver, menos propenso aos desvios ele estará. Dissemina-se a sensação de que há sempre alguém a nos observar, alguém que há de nos admoestar severamente no caso do script que nos foi imposto não ser respeitado. Um ambiente de desconfiança, permeado sobretudo pelo medo, se instala, tornando-se propício para o empoderamento de um grupo de pessoas que há de nos proteger, de nos guiar, de nos dizer o que é melhor, mesmo nas atividades mais particulares. Quem possui capital econômico e político larga na frente nessa disputa pelo comando da estrutura panóptica ${ }^{39}$ em curso. Não à toa percebemos, com cada vez mais frequência, iniciativas de autoridades constituídas que procuram nos impor, dentre outras coisas, o que comer ${ }^{40}$, ler $^{41}$, assistir ${ }^{42}$

38 FROIS, Catarina. Vigilância e poder. Lisboa: Mundos Sociais, 2011. p.25. Recomenda-se ainda: FROIS, Catarina (org). A sociedade vigilante - ensaios sobre identificação, vigilância e privacidade. Lisboa: Imprensa de Ciências Sociais, 2008.

39 No sentido desenvolvido em: BENTHAM, Jeremy. O panóptico. Belo Horizonte: Autêntica, 2000.

40 Veja-se o exemplo do Estado do Espírito Santo, onde uma lei estadual proibiu restaurantes de deixarem sal junto aos clientes nas mesas. Disponível em: http:/g1.globo.com/espirito-santo/noticia/2015/07/regulamentacaode-lei-que-proibe-sal-em-mesas-e-publicada-no-es.html. Acesso em $16 \mathrm{fev}$. 2020.

41 O Tribunal de Justiça do Estado do Rio de Janeiro, por exemplo, proibiu a venda e a divulgação do Mein Kampf, de Adolf Hitler. Disponível em: http:// g1.globo.com/rio-de-janeiro/noticia/2016/02/tj-rj-proibe-venda-e-divulgacao-de-mein-kampf-autobiografia-de-hitler.html. Acesso em 16 fev. 2020.

42 O deputado federal Marcelo Aguiar (DEM-SP), por exemplo, propôs projeto de lei (n. 6.449/2016) que impõe a criação de um mecanismo que deve interromper automaticamente, para qualquer faixa de idade, o acesso à conteúdo pornográfico que esteja disponível na internet. Disponível em: http:// congressoemfoco.uol.com.br/noticias/deputado-quer-proibir-pornografiana-internet-para-evitar-masturbacao/. Acesso em 16 fev. 2020. 
ou com quem fazer sexo e às vezes até, como fazê-lo! O controle e a vigilância, antes métodos sorrateiros, vão se expandindo despudoradamente.

Para Conceição Trigueiros ${ }^{43}$, "actualmente, o império da informática e das telecomunicações é utilizado para encarcerar informações pessoais, através de tecnologias com que Bentham nunca sonhou, o que em termos analógicos pode constituir um panóptico electronicamente reciclado!”. Nesse embalo, os espaços públicos, rapidamente, vão se amoldando às necessidades da anunciada prevenção. Tornam-se cada vez mais limpos, com a presença de poucos obstáculos ao acesso do "olho que tudo observa”. Esse tipo de ambiente, que deveria ser percebido como comum a todas as pessoas que dele quisessem usufruir, dando-lhe um significado positivo, passa a ser visto como coisa de ninguém, inclinando-o ao abandono. Vai se desenhando, assim, um cenário de certa forma hostil à ocupação. ${ }^{44}$

Evidenciado o fracasso dessa lógica, essa estruturação sistêmica, secundariamente, deve servir para identificar, e, consequentemente, punir os desviantes. Afinal, nesse tipo de contexto, à revelia da necessidade de se resolver o próprio conflito entre as partes diretamente atingidas, é sempre preciso combater a sensação de impunidade que pode pairar sobre os demais integrantes da sociedade. Controvertida a utilização da pena de morte, apenas porque livra o sujeito do necessário e pedagógico sofrimento, a inocuização acaba se alastrando como a alternativa preferida dos arautos da segurança pública. Tem-se a concentração máxima das possibilidades de controle sobre o corpo humano. ${ }^{45}$ Determinam-se as vestimentas, o corte de cabelo e o comportamento de uma maneira em geral. Como se expressar durante a fala, por onde andar, para quem olhar, a que horas e em que locais poderá fazer o seu asseio, dormir, comer, receber visitas e por aí vai. No ambiente prisional, em nome da prevenção/segurança, naturalizou-se a ideia de que tudo deve estar automatizado.

43 TRIGUEIROS, Conceição. Panóptico - as ordens da vigilância. Uma arquitectura moralista. Casal de Cambra: Caleidoscópio, 2011. p. 20.

44 Sobre essa perspectiva, de maneira mais desenvolvida, recomenda-se: LEITÃO, Lúcia. Quando o ambiente é hostil - uma leitura urbanística da violência à luz de sobrados e mucambos. $2^{\mathrm{a}}$ ed. Recife: EDUFPE, 2014.

45 FOUCAULT, Michel. Vigiar e punir - história da violência nas prisões. Petrópolis: Vozes, 2005. 
Nesse passo, vigilância, controle e punição se constituem no tripé que sustenta o mantra da ordem pública, o que tem servido de fundamento às prisões cautelares que se alastram pelo Brasil. A propósito, em pelo menos cinco oportunidades a expressão ordem pública pode ser encontrada no Código de Processo Penal brasileiro (doravante CPP). Tem-se, portanto, ainda em vigência na legislação processual penal brasileira (vejase especialmente o artigo 312 do CPP), um daqueles institutos típicos de regimes autoritários, cujo conceito possui um espectro que se espalha (ou se contrai) ao sabor das conveniências, geralmente políticas, de quem está a exercer o poder punitivo. Temos, com isso, a utilização de um conceito que, como constatam Aury Lopes Jr. e Alexandre Morais da Rosa ${ }^{46}$, é "vago, impreciso, indeterminado e despido de qualquer referencial semântico".

Esse impulso expansivo dos que comandam o sistema de controle e de punição não pode ser atribuído de maneira simplória a uma das consequências da (pós-)modernidade, pois tal sempre esteve presente no curso da história humana. O próprio Barão de Montesquieu, ainda no século XVIII, lidava com o tema em sua obra. ${ }^{47}$ Ocorre que, essa expansão demandava a disseminação de uma rede bem articulada de um grupo privilegiado de pessoas que fizesse com que a informação pudesse circular com alguma regularidade entre as cadeias de comando, o que, além de demandar demasiado tempo, dificultava o controle do alto escalão sobre os mais reles subordinados. Era preciso aperfeiçoar essa dinâmica. As inovações tecnológicas possibilitaram um controle mais rápido e eficiente com a utilização de um número reduzido de pessoas. Em suma, mais concentração de poder em um menor número.

As máquinas, embora não pensem como nós, pela poderosa capacidade de captura, armazenamento e articulação de informações, assumem definitivamente um protagonismo nessa estrutura de vigilância e de controle que se sedimenta historicamente. No entanto, embora resolvam fórmulas de maneira mais ágil e eficiente, poderiam tais máquinas, no

46 LOPES JR., Aury; MORAIS DA ROSA, Alexandre. Crise de identidade da "ordem pública" como fundamento da prisão preventiva. Disponível em: https:// www.conjur.com.br/2015-fev-06/limite-penal-crise-identidade-ordem-publica-fundamento-prisao-preventiva\#_ednref1. Acesso em 16 fev. 2020.

47 MONTESQUIEU. O espírito das leis. Trad. Jean Melville. São Paulo: Martin Claret, 2004. p. 164. 
futuro, assumirem os mais variados papéis atribuídos aos seres humanos no sistema de justiça criminal? Poderiam, nesse contexto, refletir criticamente sobre um problema jurídico-criminal? Um juízo de censura ético-jurídico seria artificialmente programável? Refletiria essa máquina mais do que a própria ética de seu programador? Se, por vezes, são suficientes para lidar com o capital financeiro, decidindo os rumos de uma negociação, poderiam então essas máquinas, com base num programa computadorizado, decidirem os rumos de uma investigação criminal? Seria possível convivermos com policiais, promotores, defensores e até juízes robots? Esses seres mecanizados seriam capazes de decidir de maneira justa o estabelecimento de uma pena ou a determinação de uma prisão cautelar? São essas algumas das questões que nos inquietam diante dos argumentos sobre o uso dessas tecnologias no âmbito da investigação criminal.

Entretanto, mesmo a despeito das máquinas, o fato é que já temos no Brasil juízes que, por exemplo, têm publicado decisões tomadas com base no mero preenchimento de formulários pré-estabelecidos, questionados junto aos tribunais superiores. Decretações de prisões cautelares, e que, portanto, privam a liberdade humana, têm sido feitas dessa maneira. ${ }^{48}$ Não há de nos espantar se surgirem, em breve, programas informáticos que, com base em cálculos probabilísticos, haverão de "auxiliar" policiais, promotores, defensores e até julgadores a tomarem decisões encaradas como mais "justas" e, sobretudo, mais céleres. Na base de dados de uma dessas máquinas “inteligentes", caso levássemos em conta o que atualmente tem prevalecido no ideário seletivo do sistema de controle e de punição no Brasil, muito provavelmente teríamos como informações determinantes repassadas às máquinas o fato de a pessoa investigada ser jovem, pobre e negra. ${ }^{49}$ Razões que, segundo esse ideário, apontariam para um juízo de reprovação probabilisticamente mais inclinado à condenação.

48 No Superior Tribunal de Justiça, veja-se a decisão de revogação no HC 70.939/ MG. Disponível em: http://www.stj.jus.br/static_files/STJ/Midias/arquivos/RHC70939.pdf. Acesso em 16 fev. 2020. Já no Supremo Tribunal Federal, pode-se compulsar os autos do HC 128.880/SP. Disponível em: http:// redir.stf.jus.br/paginadorpub/paginador.jsp?docTP=TP\&docID=10350259. Acesso em 16 fev. 2020.

49 Esse tem sido, não à toa, o perfil historicamente predominante da população carcerária brasileira. Recomenda-se para aprofundamento: DEPARTAMENTO PENITENCIÁRIO NACIONAL - DEPEN. População carcerária brasileira 
Nos últimos anos nos Estados Unidos, na esteira de programas estatísticos utilizados por seguradoras, Juan Corvolán ${ }^{50}$ constatou que a inteligência artificial transcendeu o âmbito das seguradoras chegando até o direito penal. Segundo o autor, em estados como "Oregón, Oklahoma, Texas, California, Nebraska, Colorado, Indiana, Ohio, Idaho, Delaware, Washington, Arizona, Virginia y Alabama" uma dessas máquinas inteligentes já tem auxiliado juízes na fixação de sentenças. Um dos mais populares desses programas seria o COMPAS (Correctional Offender Management Profiling for Alternative Sanctions). A intenção é obter um diagnóstico que é encarado como mais preciso [para quem?] sobre a pessoa investigada, reunindo-se informações sobre seu passado, por exemplo. Programas de espionagem, como "um meio (oculto) de obtenção de prova", popularizam-se no contexto de uma sociedade que anseia por informação ${ }^{51}$. Há anos, portanto, convivemos com discussões que fervilham ao redor do mundo e que devem nos fazer refletir criticamente a esse respeito.

Uma das principais preocupações quanto ao uso das máquinas no âmbito do sistema social de controle e de punição tem sido o direito à privacidade, discutido, nesse contexto, desde meados da década de 1980 nos Estados Unidos. Em casos como United States v. Karo, 468 U.S. 705, 715 (1984); Kyllo v. United States, 533 U.S. 27, 31 (2001); e United States $v$. Jones, 132 S. Ct. 945, 948 (2012), todos eles, sem surpresas, ${ }^{52}$ relacionados

chega a mais de 622 mil detentos - Novo relatório do Infopen mostra que perfil das pessoas privadas de liberdade é de jovens, negra e de baixa escolaridade. Disponível em: http://www.justica.gov.br/noticias/populacao-carceraria -brasileira-chega-a-mais-de-622-mil-detentos. Acesso em 16 fev. 2020.

50 CORVALÁN, Juan Gustavo. El peligro de la inteligencia artificial como oráculo del sistema penal. In: Diario Infobae. Disponível em: http://www.infobae. com/opinion/2017/08/30/el-peligro-de-la-inteligencia-artificial-como-oraculo-del-sistema-penal/. Acesso em 16 fev. 2020.

51 RIBOLI, Eduardo Bolsoni. "Eu sei o que vocês fizeram no verão passado": o uso de software de espionagem como meio de obtenção de prova penal. Revista Brasileira de Ciências Criminais, v. 156, ano 27. São Paulo: RT, 2019. p. 91 ss.

52 Nesse período, sobre os esforços do governo norte-americano na disseminação de uma política contra as drogas que "justificasse" uma série de violações de direitos e garantias fundamentais, recomenda-se: FRANÇA JÚNIOR, Francisco de Assis de. Criminologia das drogas: considerações a partir do excurso biográfico entre Medellín e Rocinha. Revista Brasileira de Ciências Criminais RBCCrim, São Paulo, v. 25, n. 130, p. 269-315, abr., 2017. p. 269-315. 
com o comércio ilegal de drogas, a Suprema Corte norte-americana fez questão de refletir criticamente sobre o uso da tecnologia como meio para obtenção de provas por parte dos agentes estatais, devendo existir respeito à privacidade, que, segundo o caso de 2001, seria "the prototypical and hence most commonly litigated area of protected privacy". Privacidade que, dadas as atuais circunstâncias, ${ }^{53}$ em que já se consegue informações sem que as pessoas precisem colaborar, com câmeras de reconhecimento facial, ${ }^{54}$ entre outros recursos,${ }^{55}$ deve também ser mental. O fato é que, mesmo com a vigência da Lei de Proteção de Dados (13.709/2018), em que são prescritas regras para a recolha das informações, sendo essas muito genéricas (art. $7^{\circ} \mathrm{ss}$ ) e permissivas (art. $4^{\circ}$ ), justamente no trato de questões de segurança pública/nacional.

O pior é que, segundo perspectivamos, ao invés de nos preocuparmos em criar mecanismos para frear essa invasão de tantos recursos investigativos, sobretudo aqueles invasivos à privacidade, à intimidade ou ao direito de não produzir prova contra si mesmo, o que nos parece é que temos feito o inverso, estimulando um cenário de verdadeira expansão, em que se possibilita a utilização desses mesmos mecanismos por outras pessoas eventualmente interessadas na investigação, como são, por exemplo, os detetives particulares e os profissionais da advocacia, cujo Provimento n. 188/2018 do Conselho Federal da Ordem dos Advogados do Brasil nos parece ser mais um instrumento (preponderantemente) de cunho político (ainda que na melhor acepção da palavra), para demarcar posição frente ao empoderamento das agências estatais repercutidas em operações como a lava-jato, do que propriamente um recurso inovador e efetivo de equilíbrio entre acusação e defesa no âmbito da investigação.

53 AIRES DE SOUSA, Susana. Neurociências e Direito Penal: em busca da "verdade" perdida (na mente)? Coimbra: Instituto Jurídico, 2017. Disponível em: https://ij.fd.uc.pt/publicacoes/vulnerabilidade_e_direito/direitonumahora2.pdf. Acesso em 16 fev. 2020.

54 VALENTE, Jonas. Tecnologias de reconhecimento facial são usadas em $37 \mathrm{ci}$ dades no país. Disponível em: http://agenciabrasil.ebc.com.br/geral/noticia/2019-09/tecnologias-de-reconhecimento-facial-sao-usadas-em-37-cidades-no-pais. Acesso em 15 nov. 2019.

55 Nesse contexto, é particularmente relevante o dossiê "Novas tecnologias e processo penal”, publicado na Revista Brasileira de Direito Processual Penal. Disponível em: http://dx.doi.org/10.22197/rbdpp.v5i3. Acesso em 18 fev. 2020. 
Assente-se, entretanto, que não vemos a iniciativa do Conselho Federal da advocacia com qualquer vício de inconstitucionalidade pela via formal, tendo em vista poder argumentar-se ser o provimento um desdobramento do princípio da ampla defesa e do contraditório (art. 5º, inciso LV, da Constituição da República). Não nos parece ser especificamente esse o problema. O provimento não veda, por exemplo, que o profissional da advocacia se utilize das provas na condição de assistente de acusação. Ainda que o provimento sinalize que a utilidade de uma investigação defensiva estaria vinculada ao asseguramento de "direitos individuais" (art. 3, inciso XI), deles também gozam as supostas vítimas e seus parentes, que, não raramente, acompanham de perto os desdobramentos da persecução contra o investigado, constituindo-se integrantes da advocacia para fazê-lo de maneira mais técnica. Estamos, na realidade, ao invés de fortalecendo o princípio da ampla defesa e do contraditório, dando uma dimensão ainda maior a ideia de uma ampla investigação, o que serve, na prática, para desprestigiar a intimidade da vida privada e, por tabela, a própria dignidade humana. Como preservá-la, afinal, como condição básica para a existência de um ambiente democrático, com a intimidade da vida privada, um de seus núcleos, cada vez mais espartilhada? O regramento parece-nos mais ter marcado uma posição política contra a atuação dos órgãos investigatórios oficiais do que propriamente equilibrado o jogo persecutório entre alguns agentes estatais e a advocacia, com o que se convencionou denominar por necessária "paridade de armas", perspectivada, segundo a doutrina de Welton Roberto ${ }^{56}$, como essência do contraditório democrático.

Ocorre que, a mentalidade inquisitiva que permeia culturalmente a persecução penal brasileira, ${ }^{57}$ que paira inclusive sobre boa

56 ROBERTO, Welton. Paridade de armas no processo penal. Belo Horizonte: Fórum, 2011. p. 93.

57 Desenvolvidamente a respeito: SANTOS, Bruno C. L.; FRANÇA JÚNIOR, Francisco A.; SANTOS, Hugo L. R. Práticas judiciárias no campo criminal e a construção das verdades na persecução penal: um debate a partir de Michel Foucault. Revista Brasileira de Direito Processual Penal, Porto Alegre, vol. 5, n. 2, p. 1041-1072, mai./jun. 2019. https://doi.org/10.22197/rbdpp.v5i2.199. E ainda: GLOECKNER, Ricardo Jacobsen. Autoritarismo e processo penal: uma genealogia das ideias autoritárias no processo penal brasileiro, v. 1. Florianópolis: Tirant lo blanch, 2018. 
parte da advocacia, não tarda, certamente há de encontrar caminhos e/ou atalhos para que uma investigação, que se pretendia como essencialmente defensiva e garantidora dos direitos individuais dos mais débeis, ${ }^{58}$ sirva-se também como aquelas do tipo acusatória. Logo, nesse cenário, não será apenas a pessoa investigada a afetada por essa criticável expansão do poder investigativo, mas todas aquelas envolvidas com o fato. Se nem as pessoas investigadas, perspectivadas como as mais débeis na relação com os agentes estatais, são poupadas desse processo invasivo, imaginemos então testemunhas, peritos e mesmo juízes, promotores e a própria advocacia. Afinal, será também preciso saber se estão dizendo aquilo que realmente sabem e/ou acreditam que seja a perseguida verdade. E para isso as máquinas, com o selo da cientificidade, apresentar-se-iam como muito úteis. Não nos parece que seja este, portanto, o caminho a ser trilhado, sobretudo porque os exemplos negativos do desvirtuamento de proposta bem intencionadas abundam na literatura. ${ }^{59}$

A opção pela expansão do poder investigatório, como um inegável corolário do próprio poder punitivo (jus puniendi), ainda que eventualmente tenha sido impulsionada por boas intenções, demonstranos a capacidade de reinvenção de um tipo de mentalidade (o que lhe tem permitido desembaraçada circularidade) ainda tributária da busca pela verdade real, o que, não raramente, pode se prestar a legitimar, por exemplo, "inúmeras técnicas de obtenção da confissão do acusado e intimidação da defesa" ${ }^{60}$. A ampla defesa e o contraditório, portanto, da nossa perspectiva, deveria servir para conter, limitar, estancar, obstaculizar a circularidade do poder punitivo e de seus corolários, jamais para se apropriar dessa mesma mentalidade, expandindo-a, portanto, dando-lhe ainda mais substância prática, mesmo que sob o argumento "em favor do investigado".

58 Esse é mote principal, aliás, da obra: FERRAJOLI, Luigi. Direito e razão - teoria do garantismo penal. 4. ed. Trad. Luiz Flávio Gomes. São Paulo: RT, 2014.

59 FRANÇA JÚNIOR, Francisco de Assis de. O grande encarceramento: só a descriminalização "salva”. Boletim IBCCRIM, São Paulo, ano 25, n. 290, p. 14-16, jan. 2017.

60 PACELLI, Eugênio. Curso de Processo Penal. 21. ed. São Paulo: Atlas, 2017. p. 340 . 
Caminhamos, portanto, para o que Marco Aurélio de Castro Júnior ${ }^{61}$, ainda que em outro contexto, denominaria de pós-humanidade, o despertar de um admirável mundo novo ${ }^{62}$, uma era que deve nos arrastar a discussões sobre uma eventual obsolescência do ser humano frente a determinadas tarefas da dinâmica social, uma delas, dizemos nós, a de ter que prevenir e resolver conflitos. Ferramentas que surgem como auxiliares, podem, com o tempo, ser apresentadas como substitutas mais eficientes das atividades desenvolvidas pelos seres humanos. Patrulhas, investigações e julgamentos realizados por robots, dotados da mais avançada inteligência artificial, repletos dos mais complexos algoritmos, programados para a produção de "justiça”. Um sistema do tipo fast trial, com respostas uniformizadas e rápidas, moldado especialmente para uma sociedade que tem pressa.

Não é de nos surpreender o fato de que já exista inteligência artificial adaptada para o meio jurídico capaz de ouvir perguntas no mesmo nível de linguagem que dois advogados experientes utilizariam para debater sobre um caso, e respondê-las com base na legislação, na jurisprudência e na doutrina, pesquisando em todas as fontes de informação relevantes para o objeto de pesquisa. ${ }^{63}$ Também estão à mão mecanismos que buscam as movimentações processuais e entregam dados relevantes aos interessados. Intimações chegam instantaneamente nos e-mails dos patronos das causas que tramitam nos mais diferentes tribunais, assim como todos os resultados dos julgamentos mais importantes. A compilação de informações fica cada vez mais precisa, a fim de que as metas sejam traçadas e cumpridas. Parcerias entre órgãos de classe e o Poder Público podem vir a criar desde controles mais agudos como um escritório virtual que concentra todos os dados de processos em diferentes plataformas ${ }^{64}$,

61 CASTRO JÚNIOR, Marco Aurélio de. Direito e Pós-Humanidade - quando os robôts serão sujeitos de Direito. Curitiba: Juruá, 2013.

62 HUXLEY, Aldous. Admirável mundo novo. Trad. Vidal Serrano. São Paulo: Globo de Bolso, 2015.

63 ASHLEY, Kevin D. Artificial Intelligence and Legal Analytics: New Tools for Law Practice in the Digital Age. Cambridge: Cambridge University Press, 2017. p. 351 ss.

64 BRASIL. Conselho Nacional de Justiça. Escritório Digital. Disponível em: http://www.cnj.jus.br/tecnologia-da-informacao/escritorio-digital. Acesso em 16 fev. 2020c. 
até simples aplicativos que ajudam advogados na organização do tempo em virtude de eventuais atrasos no início das audiências. ${ }^{65}$

No entanto, não nos parece que a complexidade ínsita às relações humanas, sobretudo aquelas de cunho conflituoso, venha a ser processada sempre satisfatoriamente numa máquina cujas respostas estão previamente prescritas em sua programação. Por menor que seja uma alegada margem de erro, o certo é que esta não há de compensar o que está em jogo: a preservação da dignidade humana, porque esta é o valor nuclear inegociável de uma nação que se apresenta como democracia. Pior ainda quando o conflito ameaçar a liberdade ambulatorial de quem quer que seja. É imperioso reconhecer que cada conflito carrega consigo um drama em particular, um cenário cujas características são únicas e, portanto, irrepetíveis.

Apesar de termos em conta que existem diversas tarefas repetitivas, ao tratarmos de funções executadas por aqueles que se dedicam às carreiras jurídicas - como a pesquisa jurisprudencial ou o protocolo de petições - há determinados atos que demandam a atenção de um ser humano, devido ao seu grau de complexidade. Interações humanas desencriptadas são necessárias para a formulação de respostas a questões que não são sujeitas a uma antecipação, a um padrão estabelecido previamente por linhas de código. ${ }^{66}$ Aliás, está fora de questão o reconhecimento do direito de autodeterminação das máquinas tal como existe para os seres humanos, isso pelo simples fato de que, nesse contexto, somente aos humanos é possível o reconhecimento de uma dignidade, bem como o desenvolvimento de uma capacidade de agir através da perspectiva ética. ${ }^{67}$ Por mais aprimorada que seja a inteligência artificial, por mais

65 BRASIL. Tribunal Regional do Trabalho da $2^{\text {a }}$ Região. Aplicativo vai informar a hora exata de início das audiências. Disponível em: http://trt2.jus.br/indicenoticias-em-destaque/21375-aplicativo-do-trt-2-vai-informar-a-hora-exatade-inicio-das-audiencias. Acesso em 16 fev. 2020.

66 REMUS, Dana; LEVY, Frank S. Can robots be lawyers? Computer, lawyers, and the practice of law. Disponível em: https://ssrn.com/abstract=2701092. Acesso em16 fev. 2020.

67 MIRANDA BARBOSA, Mafalda. Inteligência artificial, e-persons e direito: desafios e perspectivas. In: Congresso Direito e Robótica. Auditório da Faculdade de Direito da Universidade de Coimbra. 16 de nov. 2017. 
arguto que seja seu programador, suas respostas estão condicionadas ao que foi possível antecipar no curso de sua programação.

$\mathrm{O}$ aprimoramento que se deve buscar para que tenhamos um sistema de prevenção e de resolução de conflitos efetivamente justo não é propriamente nas ferramentas disponibilizadas, embora isso também seja importante, mas na capacidade dos próprios seres humanos para lidar satisfatoriamente com todas essas inovações na dinâmica social, fazendo-os perceber sobretudo que a utilização de nenhuma tecnologia deve servir para justificar ofensas aos valores diretamente ligados à dignidade da pessoa humana. A incolumidade da integridade física e mental, da intimidade da vida privada, da autodeterminação, dentre outros valores substancialmente importantes em ambiente que se pretende democrático, precisa de uma mente humana (veja-se o que dissemos no item 2) a pensar sobre suas implicações num conflito entre seres humanos cujas vidas não cabem nas fórmulas algoritmas que servem para mover as máquinas dotadas de alguma inteligência artificial.

\section{Conclusão}

Como foi possível antever, uma sociedade dirigida por máquinas já não é mais um cenário projetado por autores com mentes férteis para a disseminação de distopias. Forçoso reconhecermos que contemporaneamente a dinâmica social tem sido, em boa medida, fruto das respostas oferecidas por inteligências artificiais. Nossos desejos e comportamentos, se não (ainda) absolutamente controlados, são sorrateiramente direcionados a partir dos rastros que deixamos quando nos conectamos com a rede mundial de computadores. $\mathrm{O}$ fato é que estamos todos de alguma forma conectados por essas máquinas que, embora não pensem, são dotadas de uma desmedida capacidade de execução de tarefas para as quais levaríamos um tempo relevante. O fluxo e o registro das informações que recebem só tendem a crescer, o que certamente servirá para fomentar um sistema de controle e de punição ainda mais poderoso e invasivo. Ainda que o futuro seja permeado de incógnitas, ${ }^{68}$ não será preciso muito esforço

68 CESARI, Claudia. Editoriale: L'impatto delle nuove tecnologie sulla giustizia penale - un orizzonte denso di incognite. Revista Brasileira de Direito 
para percebermos que restará implicada a intimidade, a privacidade e a própria dignidade. O que nos interessa é começarmos a discutir, o quanto antes, dentro e fora da academia, como serão estabelecidos os necessários limites sobre essa entusiasmada atuação investigativa.

A propósito, se considerarmos o Direito como um processo social de adaptação, podemos enxergar o tema aqui proposto a partir do conceito de círculos sociais trazido pelo jurista alagoano Pontes de Miranda, ainda na década de 1920, pois a interação social, que lhe dá o elemento qualitativo, está passando por adaptações capazes de trazer valores que justificariam novas instituições. A regular evolução da sociedade é, portanto, para o crescimento dos tais círculos, de modo que as novas tecnologias, a inteligência artificial e todos os efeitos advindos delas, estariam sendo gradativamente absorvidos e organizados em nosso meio. ${ }^{69}$ Assim, o que nos parece problemático é que esse expansionismo, tanto de métodos quanto de investigadores, na prática voltado para impactar (mais negativa do que positivamente) na busca pelo que se idealiza como verdade, merece urgentemente instrumentos de contenção, e não de alargamentos, por mais bem intencionados que se anunciem.

Por fim, o presente trabalho, longe de nutrir a pretensão de apresentar respostas conclusivas, traz reflexões críticas sobre a temática proposta abordando possíveis influências negativas sobre o sistema de controle e de punição. Não obstante, concluímos que, se deixarmos que a formulação de políticas públicas em segurança continue embalada pela lógica beligerante da tolerância zero, ou com base no argumento de que, em nome da segurança, se haverá sempre de ampliar o círculo investigativo sobre o cidadão (afinal, quem não deve não teme), ou mesmo agora com lastro na ideia da paridade entre acusação e defesa, como argumento inovador, com fórmulas que, muito longe de se constituírem como inovadoras, são historicamente fracassadas, muito provavelmente desaguaremos num cenário em que zero, para além de um dos mais usuais componentes de um algoritmo, deverá ser o número de direitos e garantias que nos vai ser possível invocar diante de uma eventual investigação criminal.

Processual Penal, Porto Alegre, vol. 4, n. 3, p. 1167-1188, set./dez. 2019.

69 MIRANDA, Pontes de. Sistema de ciência positiva do Direito. $2^{\mathrm{a}}$ ed. Campinas: Bookseller, 2005. Tomo I. 


\section{REFERÊNCIAS}

AIRES DE SOUSA, Susana. Neurociências e Direito Penal: em busca da "verdade" perdida (na mente)? Coimbra: Instituto Jurídico, 2017. Disponível em: https:// ij.fd.uc.pt/publicacoes/vulnerabilidade_e_direito/direitonumahora2.pdf. Acesso em 20 nov. 2017

ASIMOV, Isaac. Eu, Robot. Trad. Eduardo Saló, José Teixeira de Aguilar e Mário Redondo. Mem Martins: Europa-América, 2004.

ASIMOV, Isaac. O homem bicentenário e outras histórias. Trad. Milton Persson. Porto Alegre: L\&PM, 1997.

ASIMOV, Isaac. Visões de um robot. Trad. Eduardo Saló. Mem Martins: Europa -América, 1992.

BENTHAM, Jeremy. O panóptico. Belo Horizonte: Autêntica, 2000.

ASHLEY, Kevin D. Artificial Intelligence and Legal Analytics: New Tools for Law Practice in the Digital Age. Cambridge: Cambridge University Press, 2017.

CASTRO JÚNIOR, Marco Aurélio de. Direito e Pós-Humanidade - quando os robôts serão sujeitos de Direito. Curitiba: Juruá, 2013.

CANÁRIO, Pedro. Quase 110 milhões de processos passaram pelo Judiciário em 2016, segundo CNJ. Disponível em: https://www.conjur.com.br/2017-set-04/110-milhoes-processos-passaram-judiciario-2016. Acesso em 21 nov. 2017.

CESARI, Claudia. Editoriale: L'impatto delle nuove tecnologie sulla giustizia penale - un orizzonte denso di incognite. Revista Brasileira de Direito Processual Penal, Porto Alegre, vol. 4, n. 3, p. 1167-1188, set./dez. 2019. https://doi.org/10.22197/ rbdpp.v5i3.292

CONNER-SIMONS, Adam; GORDON, Rachel. Detecting emotions with wireless signals. Disponível em: https://www.csail.mit.edu/detecting_emotions_with_wireless_signals. Acesso em: 24 out. 2017.

CORVALÁN, Juan Gustavo. El peligro de la inteligencia artificial como oráculo del sistema penal. In: Diario Infobae. Disponível em: http://www.infobae.com/ opinion/2017/08/30/el-peligro-de-la-inteligencia-artificial-como-oraculo-delsistema-penal/. Acesso em 20 nov. 2017.

CROSSEN, Cynthia. O fundo falso das pesquisas - a ciência das verdades torcidas. Trad. Roberto Teixeira. Rio de Janeiro: Revan, 1996. 
D’ANGELO, Helô. Vem aí: lentes de contato de realidade virtual - A Samsung acaba de registrar uma patente para a produção de lentes com microcâmeras integradas e conexão wi-fi. Disponível em: https://super.abril.com.br/tecnologia/vem-ai -lentes-de-contato-de-realidade-virtual/. Acesso em 24 out. 2017.

DEPARTAMENTO PENITENCIÁRIO NACIONAL - DEPEN. População carcerária brasileira chega a mais de 622 mil detentos - Novo relatório do Infopen mostra que perfil das pessoas privadas de liberdade é de jovens, negra e de baixa escolaridade. Disponível em: http://www.justica.gov.br/noticias/populacao-carceraria-brasileira-chega-a-mais-de-622-mil-detentos. Acesso em 20 nov. 2017.

FERRAJOLI, Luigi. Direito e razão - teoria do garantismo penal. 4. ed. Trad. Luiz Flávio Gomes. São Paulo: RT, 2014.

FOUCAULT, Michel. Vigiar e punir - história da violência nas prisões. Petrópolis: Vozes, 2005.

FRANÇA JÚNIOR, Francisco de Assis de. O grande encarceramento: só a descriminalização “salva”. Boletim IBCCRIM, São Paulo, ano 25, n. 290, p. 14-16, jan. 2017.

FRANÇA JÚNIOR, Francisco de Assis de. Criminologia das drogas: considerações a partir do excurso biográfico entre Medellín e Rocinha. Revista Brasileira de Ciências Criminais - RBCCrim, São Paulo, v. 25, n. 130, p. 269-315, abr., 2017.

FROIS, Catarina. Vigilância e poder. Lisboa: Mundos Sociais, 2011.

FROIS, Catarina (org). A sociedade vigilante - ensaios sobre identificação, vigilância e privacidade. Lisboa: Imprensa de Ciências Sociais, 2008.

GABBATT, Adam. IBM computer Watson wins Jeopardy clash. Disponível em: https://www.theguardian.com/technology/2011/feb/17/ibm-computer-watsonwins-jeopardy. Acesso em 22 nov. 2017.

GARDNER, Howard. A nova ciência da mente - uma história da Revolução Cognitiva. Trad. Inês Ricardo, Lisboa: Relógio D’Água, 2002.

GLINK, Llyce. 9 ways drones are changing real estate. Disponível em: https:// www.cbsnews.com/media/9-ways-drones-are-changing-real-estate/. Acesso em 22 nov. 2017.

GLOECKNER, Ricardo Jacobsen. Autoritarismo e processo penal: uma genealogia das ideias autoritárias no processo penal brasileiro, v. 1. Florianópolis: Tirant lo blanch, 2018

GREGOIRE, Carolyn. Scientists Have Figured Out How To 'Fingerprint' Your Brain The technology could be used to predict mental or neurological illness. Disponível 
em: https://www.huffingtonpost.com/entry/brain-connections-map_us_582b628be4b01d8a014adc56. Acesso em: 11 nov. 2017.

HAWKING, Stephen. Conferência de abertura da Web Summit em Lisboa, Portugal. Disponível em: https://www.youtube.com/watch?time_continue=13\&v=U-hcSLya0_w. Acesso em 14 nov. 2017.

HELM, Gerhard. Computer können denken! Der Mensch in der Perspektive der Kognitionswissenschaft. Frankfurt am Main: Suhrkamp, 1998.

HUXLEY, Aldous. Admirável mundo novo. Trad. Vidal Serrano. São Paulo: Globo de Bolso, 2015.

KURZWEIL, Ray. How to Create a Mind: The Secret of Human Thought Revealed. London: Duckworth Overllok, 2013.

KURZWEIL, Ray. The age of spiritual machines: when computer exceed human intelligence. New York: Penguin Books, 1999.

KURZWEIL, Ray. The singularity ir near: when humans transcend biology. London: Duckworth Overllok, 2008.

LEAL AMADO, João. Os robots e o direito do trabalho: o desafio final? In: Congresso Direito e Robótica. Auditório da Faculdade de Direito da Universidade de Coimbra. 16 de nov. 2017.

LEITÃO, Lúcia. Quando o ambiente é hostil - uma leitura urbanística da violência à luz de sobrados e mucambos. $2^{\mathrm{a}}$ ed. Recife: EDUFPE, 2014.

LEONARDI, Ana Carolina. Cientistas conseguem apagar memórias ruins em ratos - Eles descobriram que, manipulando um neurotransmissor, conseguem deletar traumas e até reforçar memórias boas. Disponível em: https://super.abril.com. $\mathrm{br} /$ ciencia/cientistas-conseguem-apagar-memorias-ruins-em-ratos/. Acesso em 24 out. 2017.

LOPES JR., Aury; MORAIS DA ROSA, Alexandre. Crise de identidade da "ordem pública” como fundamento da prisão preventiva. Disponível em: https://www. conjur.com.br/2015-fev-06/limite-penal-crise-identidade-ordem-publica-fundamento-prisao-preventiva\#_ednref1. Acesso em 16 nov 2017.

MARSHALL, Aarian. What does tesla's automated truck mean for truckers? Disponível em: https://www.wired.com/story/what-does-teslas-truck-mean-for-truckers/. Acesso em 21 nov. 2017.

MARTINHO, Rui Leão (dir.). Cadernos de economia, Lisboa, ano XXX, n. 119, abr/jun, 2017. 
McCORDUCK, Pamela. Machines Who Think. São Francisco: W.H. Freeman, 1979. MIRANDA BARBOSA, Mafalda. Inteligência artificial, e-persons e direito: desafios e perspectivas. In: Congresso Direito e Robótica. Auditório da Faculdade de Direito da Universidade de Coimbra. 16 de nov. 2017.

MIRANDA, Pontes de. Sistema de ciência positiva do Direito. $2^{\mathrm{a}}$ ed. Campinas: Bookseller, 2005. Tomo I.

MONTESQUIEU. O espírito das leis. Trad. Jean Melville. São Paulo: Martin Claret, 2004.

NEVEJANS, Nathalie. Quel statu juridique pour les robots autonomes? A propos de l'article 59, f), de la Résolution du Parlament européen du 16 février 2017 sur les règles de droit civil sur la robotique. In: Congresso Direito e Robótica. Auditório da Faculdade de Direito da Universidade de Coimbra. 16 de nov. 2017.

NOVET, Jordan. Tesla is working with AMD to develop its own A.I. chip for selfdriving cars, says source. Disponível em: https://www.cnbc.com/2017/09/20/ tesla-building-an-ai-chip-for-its-cars-with-amd.html. Acesso em 21 nov. 2017.

ORWELL, George. 1984. Trad. Heloisa Jahn. São Paulo: Companhia das Letras, 2009. PACELLI, Eugênio. Curso de Processo Penal. 21. ed. São Paulo: Atlas, 2017.

PENROSE, Roger. O grande, o pequeno e a mente humana - com Abner Shimony, Nancy Cartwright e Stephen Hawking. Trad. David Resendes. Lisboa: Gradiva, 2003.

PENROSE, Roger. A mente virtual (the emperor's new mind) - sobre computadores, mentes e as leis da física. Trad. Augusto José Franco de Oliveira, Carlos Lourenço e Luís Teixeira da Costa. Lisboa: Gradiva, 1997.

PEREIRA, Luís Moniz. A máquina iluminada - cognição e computação. Porto: Fronteira do Caos, 2016.

PESSIS-PASTERNAK, Guitta. Será preciso queimar Descartes? Do caos à inteligência artificial: quando os cientistas se interrogam. Lisboa: Relógio D’Água, 1993.

PINTO, Rita. Sophia, a robot que já tem mais direitos que as mulheres na Arábia Saudita. Disponível em: https://shifter.pt/2017/10/sophia-robot-arabia-saudita/. Acesso em 16 nov. 2017.

PINTO MONTEIRO, António. Intervenção de abertura. Congresso Direito e Robótica. Auditório da Faculdade de Direito da Universidade de Coimbra. 16 de nov. 2017. 
REMUS, Dana; LEVY, Frank S. Can robots be lawyers? Computer, lawyers, and the practice of law. Disponível em: https://ssrn.com/abstract=2701092. Acesso em 22 nov. 2017.

RIBOLI, Eduardo Bolsoni. "Eu sei o que vocês fizeram no verão passado": o uso de software de espionagem como meio de obtenção de prova penal. Revista Brasileira de Ciências Criminais, São Paulo, v. 156, ano 27, jun. 2019.

ROBERTO, Welton. Paridade de armas no processo penal. Belo Horizonte: Fórum, 2011.

RUSSELL, Stuart J.; NORVIG, Peter. Artificial Intelligence - a modern approach. 3. ed. New Jersey: Pearson, 2010.

SANTOS, Bruno C. L.; FRANÇA JÚNIOR, Francisco A.; SANTOS, Hugo L. R. Práticas judiciárias no campo criminal e a construção das verdades na persecução penal: um debate a partir de Michel Foucault. Revista Brasileira de Direito Processual Penal, Porto Alegre, vol. 5, n. 2, p. 1041-1072, mai./jun. 2019. https://doi. org/10.22197/rbdpp.v5i2.199.

SEARLE, John. Mente, cérebro e ciência. Trad. Artur Morão. Lisboa: Edições 70, 2015.

TRIGUEIROS, Conceição. Panóptico - as ordens da vigilância. Uma arquitectura moralista. Casal de Cambra: Caleidoscópio, 2011.

VALENTE, Jonas. Tecnologias de reconhecimento facial são usadas em 37 cidades no país. Disponível em: http://agenciabrasil.ebc.com.br/geral/noticia/2019-09/ tecnologias-de-reconhecimento-facial-sao-usadas-em-37-cidades-no-pais. Acesso em 15 nov. 2019.

VENOSA, Sílvio de Salvo. Lei do inquilinato comentada: doutrina e prática. São Paulo: Atlas, 2013. 


\section{Informações adicionais e declarações dos autores (integridade científica)}

Declaração de conflito de interesses (conflict of interest declaration): os autores confirmam que não há conflitos de interesse na realização das pesquisas expostas e na redação deste artigo.

Declaração de autoria e especificação das contribuições (declaration of authorship): todas e somente as pessoas que atendem os requisitos de autoria deste artigo estão listadas como autores; todos os coautores se responsabilizam integralmente por este trabalho em sua totalidade.

- Francisco França Júnior: projeto e esboço inicial (conceptualization), desenvolvimento da metodologia (methodology), coleta e análise de dados (data curation), levantamento bibliográfico (investigation), revisão bibliográfica (investigation), redação (writing - original draft), participação ativa nas discussões dos resultados (validation), revisão crítica com contribuições substanciais (writing - review and editing), aprovação da versão final.

- Bruno Cavalcante Leitão Santos: coleta e análise de dados (data curation), levantamento bibliográfico (investigation), revisão bibliográfica (investigation), redação (writing - original draft), participação ativa nas discussões dos resultados (validation), revisão crítica com contribuições substanciais (writing - review and editing), aprovação da versão final.

- Felipe Costa Laurindo do Nascimento: coleta e análise de dados (data curation), levantamento bibliográfico (investigation), revisão bibliográfica (investigation), redação (writing - original draft), participação ativa nas discussões dos resultados (validation), revisão crítica com contribuições substanciais (writing - review and editing), aprovação da versão final. 
Declaração de ineditismo e originalidade (declaration of originality): os autores asseguram que o texto aqui publicado não foi divulgado anteriormente em outro meio e que futura republicação somente se realizará com a indicação expressa da referência desta publicação original; também atestam que não há plágio de terceiros ou autoplágio.

Dados do processo editorial (http://www.ibraspp.com.br/revista/index.php/RBDPP/about/editorialPolicies)

- Recebido em: 15/01/2020

- Controle preliminar e verificação de plágio: 19/01/2020

- Avaliação 1: 24/01/2020

- Avaliação 2: 28/01/2020

- Avaliação 3: 29/01/2020

- Avaliação 4: 01/02/2020

- Decisão editorial preliminar: 15/02/2020

- Retorno rodada de correções: $18 / 02 / 2020$

- Decisão editorial final: 26/02/2020

\section{Equipe editorial envolvida}

- Editor-chefe: 1 (VGV)

- Editora-associada: 1 (MSG)

- Revisores: 4 
COMO CITAR ESTE ARTIGO:

FRANÇA JÚNIOR, Francisco; SANTOS, Bruno C. L.; NASCIMENTO, Felipe C. L. Aspectos críticos da expansão das possibilidades de recursos tecnológicos na investigação criminal: a inteligência artificial no âmbito do sistema de controle e de punição. Revista Brasileira de Direito Processual Penal, Porto Alegre, vol. 6, n. 1, p. 211-246, jan./abr. 2020. https://doi.org/10.22197/rbdpp.v6i1.334

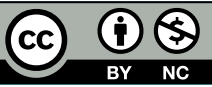

Esta obra está licenciada com uma Licença Creative Commons Atribuição-NãoComercial 4.0 Internacional. 